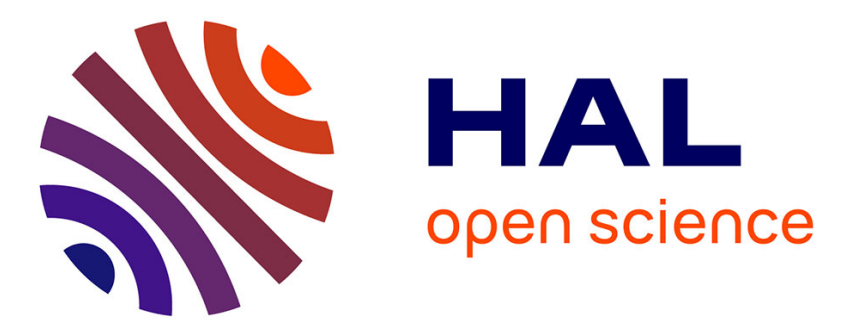

\title{
Bargaining local compensation payments for the installation of new power transmission lines
}

\author{
Olivier Joalland, Jean-Christophe Pereau, T. Rambonilaza
}

\section{To cite this version:}

Olivier Joalland, Jean-Christophe Pereau, T. Rambonilaza. Bargaining local compensation payments for the installation of new power transmission lines. Energy Economics, inPress, 80 (May), pp.75-85. 10.1016/j.eneco.2018.12.007 . hal-02485122

\section{HAL Id: hal-02485122 \\ https://hal.science/hal-02485122}

Submitted on 21 Oct 2021

HAL is a multi-disciplinary open access archive for the deposit and dissemination of scientific research documents, whether they are published or not. The documents may come from teaching and research institutions in France or abroad, or from public or private research centers.
L'archive ouverte pluridisciplinaire $\mathbf{H A L}$, est destinée au dépôt et à la diffusion de documents scientifiques de niveau recherche, publiés ou non, émanant des établissements d'enseignement et de recherche français ou étrangers, des laboratoires publics ou privés.

\section{다)(1) $(5$}

Distributed under a Creative Commons Attribution - NonCommercial| 4.0 International 


\title{
Bargaining local compensation payments for the installation of new power transmission lines
}

\author{
Olivier Joalland ${ }^{\mathrm{a}}$, Jean-Christophe Pereau ${ }^{\mathrm{b}}$, Tina Rambonilaza ${ }^{\mathrm{c}, *}$ \\ arstea, UR ETBX, 50 avenue de Verdun, Cestas F-33612, France \\ ${ }^{\mathrm{b}}$ GREThA UMR - CNRS 511, Bordeaux University, Avenue Léon Duguit, 33608 Pessac CEDEX, France \\ 'Irstea, UR ETBX, 50 avenue de Verdun, Cestas F-33612. France
}

\section{A R T I C L E I N F O}

\section{Article history:}

Received 6 April 2018

Received in revised form 3 December 2018

Accepted 13 December 2018

Available online 29 December 2018

\section{JEL classification:}

C71

L43

L94

\section{Keywords:}

Transmission planning

Compensations

Damages

Local acceptance

Nash bargaining solution

Negotiation protocols

\begin{abstract}
A B S T R A C T
This paper analyzes transmission system operator (TSO)-host community negotiations over an efficient and socially-optimal compensation payment for the installation of new electric power transmission lines. We consider that the TSO has an incentive to negotiate over a transfer that will become a function of final demand. We thus develop a bargaining game within a vertical relationship framework to include the distribution system operator (DSO) and the end-users at the downside of the bargaining problem. We determine the equilibrium of the game, for three negotiation protocols (sequential, bilateral, and multilateral) as an alternative to the non-cooperative situation. We show that when the number of municipalities involved in the process is higher than 5 , the multilateral bargaining procedure is the most profitable for all agents, including the municipalities. Inversely, when the number of municipalities is lower than 5 , different cases can arise. A single municipality will prefer the non-cooperative outcome while municipalities will prefer the sequential case when there are 2 or the bilateral case when there are 3 or 4 . However, from the TSO standpoint and for the society, multilateral negotiations are always the best outcome.
\end{abstract}

(c) 2018 Elsevier B.V. All rights reserved.

\section{Introduction}

Integrating renewable electricity sources into the existing infrastructure has created a need for greater transmission capacity. This is necessary in order to continue to meet electricity demand while providing a reliable, stable, and secure supply. It is estimated that some 150 billion euros will be invested in around $48,000 \mathrm{~km}$ of new or upgraded high-tension power cables by 2030 in Europe (ENTSO-e, 2014). While there is widespread support among the general public for energy transition, installation of new electricity transmission infrastructure is frequently met with resistance in host communities (Cohen et al., 2016). Different aspects of the planning process of transmission project, such as procedural justice and trust in institutions, are important factors in gaining social acceptance within local communities (Devine-Wright, 2012; Keir et al., 2014). Various organizational solutions have been developed to help transmission

\footnotetext{
* Corresponding author.

E-mail addresses: olivier.joalland@irstea.fr (O. Joalland), jean-christophe.pereau@ u-bordeaux.fr (J.-C. Pereau), tina.rambonilaza@irstea.fr (T. Rambonilaza).
}

system operators (TSOs) negotiate with host communities. These range from new procedures for public participation (Komendantova and Battaglini, 2016; Tobiasson et al., 2016), to consultation and cooperation with affected stakeholders (Spath and Scolobig, 2017).

However, these procedural considerations are strengthened significantly by other type of arguments such as adequate compensation of the impacts of electricity transmission infrastructures, specifically overhead high voltage power lines, for health and aesthetic values of landscapes (Cain and Nelson, 2013). The importance of these impacts is used by locals in calling for underground cables rather than overhead ones (Atkinson et al., 2006; Navrud et al., 2008; Menges and Beyer, 2014), despite the increased costs of such options, and associated environmental and health-related drawbacks (Lienert et al., 2018). Furthermore, installing underground transmission lines is not always technically feasible, especially for very high voltages.

The role of compensation mechanisms (in-kind benefit provisioning or monetary transfer) to correct for external costs of overhead power lines, as well as garnering support for these infrastructures, has thus regained the attention of researchers (Mueller, 2016; Hyland and Bertsch, 2018) and operators (RGI, 2016). This paper adds to the current knowledge about negotiation process for host community 
acceptance of new overground projects by disentangling the complex issue of bargaining procedure for efficient and socially-optimal compensatory schemes.

Compensatory schemes are essentially an attempt to put into practice the Coase theorem, which stipulates that, if property rights over the environment asset are clearly defined, the problems of external effects can be overcome through private negotiation between affected parties (Coase, 1960). This proposal was reinforced by Kunreuther and Easterling (1996), advocating a voluntary process of site selection and negotiated compensation between the parties, rather than imposing any compensation measures based upon a uniform nationwide regulation. However, unlike single location power generation sites, transmission lines are linear infrastructures that often cross and impact multiple localities. Complex procedures to obtain acceptance of transmission projects by local populations mean that negotiations are time consuming (around six years on average in France). They also generate additional costs due to increased budgets dedicated to compensatory measures for host municipalities. Over-spending through inefficient compensation schemes without increasing the price paid by grid users on electricity tariff charged on final consumers, will inevitably lead to reduced revenue for TSO (Tobiasson and Jamasb, 2016).

Reducing the financial risk borne by the TSOs with network infrastructure projects has become an important aspect of energy transition of electric power policy in Europe. This is needed to ensure adequate innovation and investment in the expansion of the transmission grid, while keeping the grid tariff low. Sharing transmission costs between grid users and beneficiaries has thus become a part of the solution. Cooperation between main beneficiaries (TSO, producers, and distributors) in expanding electricity grids has been proved to improve social welfare, by selecting the route with the lowest costs, thus avoiding an increase in the price paid by the end user. However, in the majority of studies - even the most recent (Hasan et al., 2014; Roustaei et al., 2014; Banez-Chicharro et al., 2017)analysis was based on the assumption that local residents all supported the installation of new transmission lines. Strategic decisions related to municipalities whose residents were negatively affected were not included. One exception is Mueller (2016). His model is based on the assumption that potential host communities develop and act together to achieve the most profitable route to connect the electricity-generation sources to the demand regions. A minimumcost-spanning tree game is applied to determine the new route that minimizes the total cost for the projected grid extension, then the axiomatic Shapley value is used to determine the burden sharing of the cost between the hosting communities. With regard to the non-cooperative behaviour of communities, a single-round sealedbid auction procedure was introduced for obtaining their consent for compensation payment with the true value of their willingness to accept.

Mueller's paper, again, provides evidence that cooperative game theory could be useful (Gately, 1974 was an early example of this), to better understand the underlying process of coalition formation within potential host communities, when adding a new high voltage power line. Moreover, his paper highlights the importance of the procedure (here the sealed-bid auction) involved in negotiating compensation payments. In this paper, we focus on analyzing the effect of alternative bargaining protocols to reach agreement for a specific route of the new power line, and their outcome for the different players. This particularly applies for the innovative "Announce-Discuss-Decide" approach to infrastructure planning and siting negotiation process implemented by the French TSO Rte (Späth et al., 2014).

In doing so, our study is different from Mueller's perspective, and its novelties are as follows. Our model is based on the Nash bargaining solution (Nash, 1950) which is another cooperative game theory concept. However the Nash bargaining solution payoff can be obtained as a limit case of the strategic alternating offer model of Rubinstein (1982). In particular Binmore et al. (1986) have shown that when players are patient, the unique subgame perfect payoff of the Rubinstein model is the Nash bargaining solution. It implies that the different outcome of the bargaining protocols based on the Nash solution can be implemented in dynamic strategic models of negotiation (Krishna and Serrano, 1996; Muthoo, 1999). Our model assumes that the TSO negotiates monetary transfer directly with host communities as compensation for accepting of a new power transmission line. We consider that compensation schemes are designed within a vertical relationship between a TSO and a DSO (Distribution System Operator). This provides a way of understanding economic interaction between two monopolistic operators when managing electricity flows. We solve and compare the outcome obtained from three negotiation protocols (bilateral, multilateral, sequential) to look at the effect that bargaining rules have on the compensation paid to host communities, the overall profit of the TSO and the DSO, consumer surplus as a function of the grid tariff, and social welfare.

The remainder of the paper is organized as follows. Section 2 briefly describes the regulatory framework in France upon which we have grounded our analysis. Section 3 details the model: its assumptions, the resolution of the non-cooperative case and the different bargaining protocols. Section 4 presents the key findings of our analysis. Section 5 concludes.

\section{Interactions between beneficiaries of a transmission line project: the French case}

In Europe, many countries have progressively restructured their electricity sector towards a more open and competitive environment for generation and retail activities (Fetz and Filippini, 2010). Yet, operation of transmission and distribution systems remain regulated monopolies (Pérez-Arriaga, 2014; Glachant and Ruester, 2014). This is the case for France. The electricity transmission network is managed by Rte and $95 \%$ of the distribution grid is managed by Enedis (and 5\% by local companies). The national TSO continues to earn the required revenue to cover its costs (including capital costs) for transmission service and system operations, from the tariff charged to electricity producers on the one side, and to the DSO which in turn passed it to electricity consumers, on the other side. Overall costs of electricity transmission are thus shared between producers and consumers. However, it should be noted that $98 \%$ of revenues from grid pricing come from electricity consumers, in accord with the European Union regulation which caps the injection tariff at $0.5 € / M W h$ (Commission, 2010). Consequently, local compensation payments are predominantly financed by the grid tariff applied by the DSO to electricity consumers (mainly composed of households).

While community benefits are to a large extent site specific, the negotiation process in itself is mainly shaped by the legal framework, and has to follow formal and official procedures provided at national level. In France, in the best of cases, going through the various different stages of the permitting procedure for a new transmission line project currently takes around six years (Rte, 2016). Negotiations for community benefits generally run after technical and environmental feasibility studies, and confirmation of the planned route by the State. The TSO has thus to develop a detailed project, which will form the basis for public consultation and negotiation with their representatives, to obtain their agreement. The host community of a transmission line project consists primarily of the host municipalities and their immediate neighbors. In the first instance, negotiations are mainly conducted with the following stakeholders: the national administrative authority representatives, local elected officials, representatives of local residents, and environmental associations. While they are mandatory, compensatory measures with the aim of mitigating adverse environmental and socioeconomic 
impacts have to play a role in a host municipality's decision to agree with or oppose a project. It could be possible to consider these feasibility studies as a first step in the negotiation process. For instance Mueller (2016) analyses in the same framework the choice of the grid extension and the way the cost will be shared. In our case, we implicitly assumed that the choice of the host municipalities needed for the transmission line has already been selected and the chosen project is the one that maximizes benefits and gives the highest surplus. Hence the question is to know how this surplus will be shared between the involved municipalities.

In the current system, the amount of the transfer to the municipality is partially determined by the size of the project. Community benefit funding takes the form of an additional budget for investments in local infrastructure or development projects, and corresponds to $10 \%$ of the infrastructure cost for a $400 \mathrm{kV}$ line and $8 \%$ of the cost for a $225 \mathrm{kV}$ line (RGI, 2016). The budget is shared between all host municipalities according to the characteristics of the route (e.g. the length of line in each municipality). In addition, the TSO has to pay an annual tax for each pylon installed in a municipality (e.g. in 2017: €4631 per $400 \mathrm{kV}$ pylon and €2318 per $225 \mathrm{kV}$ pylon).

Recent comparative reviews (Ciupuliga and Cuppen, 2013; Spath and Scolobig, 2017) have shown the effectiveness of Rte's arena of dialogue in obtaining the acceptance of local communities. However, the approach used has led to changes in rules governing the negotiation process based on a simultaneous bilateral bargaining protocol, and an increased budget for community benefit funding. Indeed, in some cases, when an agreement cannot be reached due to the veto of one or more municipalities, additional compensatory measures (including the burial of part of the line) which go beyond legal frameworks have become necessary. The nature and scope of these additional measures are predominantly determined through a bilateral negotiation between the TSO and those municipalities who are reluctant to agree. As a result, the legal framework for governing the negotiation of transmission line projects could not be considered as efficient and cost effective for regulated monopolies. Any additional expense will be included in the grid tariff and thus transferred to the end users (who are composed mainly by residential users in France), hence potentially decreasing demand. Consequently, even if investment costs are entirely covered by the grid tariff, the TSO has an incentive to control them.

The point we are making from this French situation is that the first objective of a negotiation on community benefit payments between host municipalities and the TSO is to provide a level of compensation which minimizes the overall costs of grid expansion and generates optimal grid pricing. One way to do this is to introduce the electricity demand component into the compensation scheme, and to find a bargaining protocol that explicitly specifies the rules governing the negotiation process, taking into account the problems faced by the TSO, specifically in terms of profitability.

Our analysis directly focuses on the bargaining protocol for the agents representing the TSO in negotiating compensatory payments with local municipalities. Drawing on a bargaining game embedded in a vertical relationship between the TSO and the DSO, the outcomes concerned the profit of the TSO, the transfer payment for municipalities, and the grid tariff for the final consumers. The objective is to find a negotiation procedure that is able to favor cooperation between all the municipalities involved in the project, and ensuring also that their compensation will neither increase prices for electricity consumers nor jeopardize the economic efficiency of investments made by a regulated TSO (Joskow, 2014).

\section{The model}

Let us assume that the TSO plans to build a new high voltage line on a territory formed by $n$ municipalities denoted by $i=1, \ldots, n$. To realize the project, the TSO needs to reach an agreement with each municipality involved by the new line route. For each unit of electricity passing through the line to respond to demand (denoted by $Q\left(t_{d}\right)$ ) at a tariff $t_{d}$, each municipality suffers from a level of environmental damage denoted by $d_{i}$. Total damage is then denoted by $D=\sum_{i=1}^{n} d_{i}$. To ensure an agreement with all the municipalities, the TSO has to negotiate compensation with each of them, i.e. a monetary transfer per unit of electricity denoted by $w_{i}$. The compensation is thus linked to the demand of the consumers benefiting from the new transmission line. A list of the variables and their interpretation is given in Appendix A.

The vertical relation framework in Fig. 1 appears to be relevant to take into account the interests of both the TSO and host municipalities but also to study how their negotiation outcomes impact the grid tariff paid by the DSO, before reaching the end-use consumer (Fig. 1). Vertical relations exist in industries where the value chain is segmented by upstream and downstream activities. The approach developed by Spengler (1950) and its subsequent developments (Tirole, 1988; Horn and Wolinsky, 1988; Hart et al., 1990; Rey and Vergé, 2004) investigate the relationship between a producer and a retailer: the producer (placed upstream of the value chain) sells an intermediate good to the retailer (placed downstream), who then resells the final product to the consumer. Each agent has a monopoly position on its segment and sets its tariff as a mark-up. In this analogy, the TSO is the producer (of electricity transmission services), and the DSO is the retailer serving the final demand (for an electricity access service through the distribution grid). We therefore consider that the DSO is the supplier of electricity to the consumer. Transmission and distribution of electricity can be represented as two vertically-related monopolies, meaning that the downstream firm

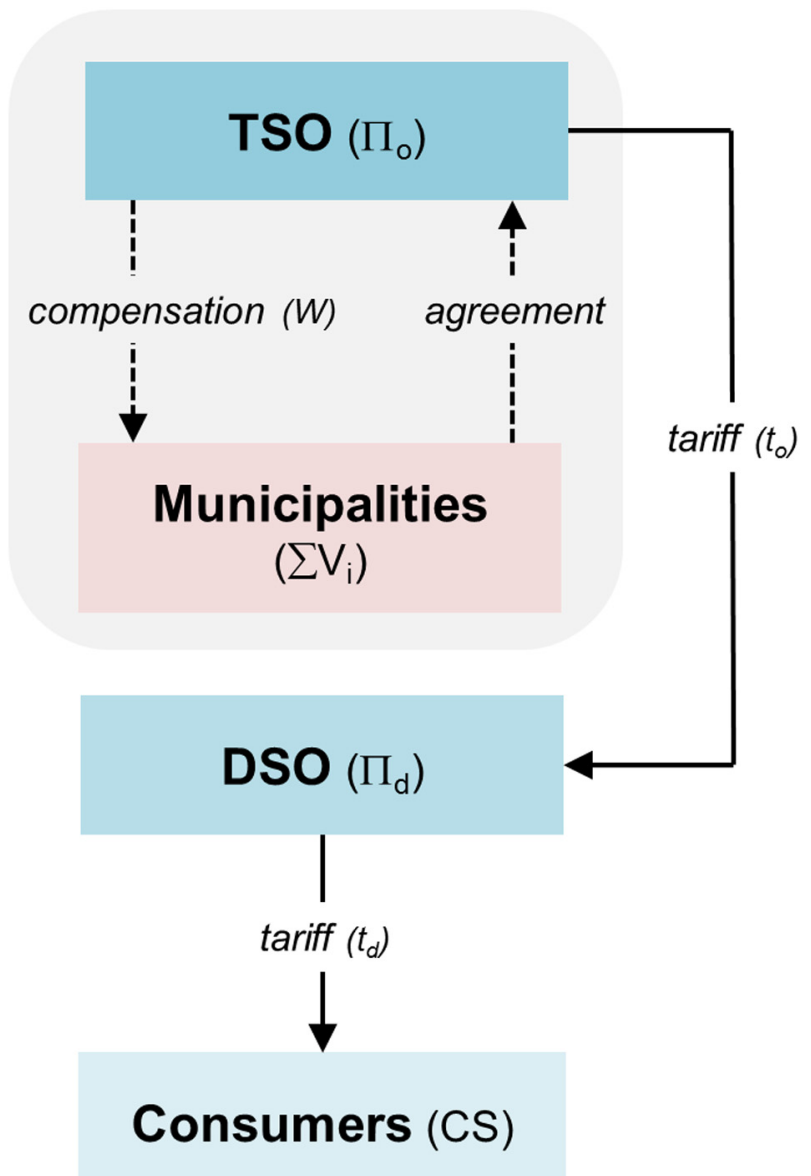

Fig. 1. A vertical relationship framework. 
(DSO) will take upstream production costs (including compensation payment) into account as a vertical externality (Tirole, 1988).

The payoff function of a host municipality is given by

$V_{i}=\left(w_{i}-d_{i}\right) Q\left(t_{d}\right)$

The TSO provides the electricity to the DSO at a tariff $t_{0}$. This tariff covers the investment cost of the line, denoted by $c_{0}$, and the total amount of monetary transfers for all the municipalities, $W=$ $\sum_{i=1}^{n} w_{i}$, for every unit of electricity transiting on the line. The payoff function of the TSO can be written as follows:

$\Pi_{o}=\left(t_{0}-W-c_{0}\right) Q\left(t_{d}\right)$

Then the DSO sells the electricity to the final consumers at a tariff $t_{d}$. We also assume that the DSO bears a cost $c_{d}$. The payoff function of the DSO is

$\Pi_{d}=\left(t_{d}-t_{0}-c_{d}\right) Q\left(t_{d}\right)$

The final demand is assumed to be linear and decreasing with $t_{d}$ :

$Q\left(t_{d}\right)=a-b t_{d}$

where $a>0$ stands for the intercept of the demand function and can be interpreted as the maximum transit capacity of the new line. Coefficient $b>0$ is the slope of the demand function. Based on Eq. (4), the consumers surplus is then

$C S=\int_{t_{d}}^{a / b} Q\left(t_{d}\right) \cdot d t_{d}=\frac{1}{2 b}\left(a-b t_{d}\right)^{2}$

From Eqs. (1)-(3) and (5), the social welfare is defined as the sum of all payoffs of the municipalities $V=\sum_{i=1}^{n} V_{i}$, operators - TSO $\left(\Pi_{0}\right)$ and DSO $\left(\Pi_{d}\right)$ - and consumers (CS):

$S W=V+\Pi_{o}+\Pi_{d}+C S$

\subsection{The non-cooperative outcome}

In this benchmark situation, we assume no negotiation between TSO and the municipalities. Each municipality maximizes his payoff given by Eq. (1) with respect to his decision variable $w_{i}$. The solution of the program

$\max _{w_{i}} V_{i}$

gives the optimal compensation transfer

$w_{i}^{N C}=d_{i}+\frac{1}{(1+n)} \frac{X}{b}$

where $X=a-b\left(c_{d}+c_{0}+D\right)>0$ stands for the created surplus along the chain value. By assumption this term is positive meaning that the demand is high enough to compensate the cost borne by the TSO and the DSO and the damages of the municipalities. All these coefficients are assumed to be known without uncertainty.

The TSO maximizes his payoff given by Eq. (2) with respect to his decision variable $t_{0}$

$\max _{t_{0}} \Pi_{0}$ which gives the optimal tariff

$t_{o}^{N C}=\frac{a}{b}-c_{d}-\frac{1}{2(1+n)} \frac{X}{b}$

Finally the DSO maximizes his payoff given by Eq. (3) with respect to his decision variable $t_{d}$

$\max _{t_{d}} \Pi_{d}$

which gives the optimal tariff

$t_{d}^{N C}=\frac{a}{b}-\frac{1}{4(1+n)} \frac{X}{b}$

The details of the derivation are given in Appendix A.

From the above expressions, we obtain the payoff for each agent:

$V_{i}^{N C}=\frac{1}{4(n+1)^{2}} \frac{X^{2}}{b} ; \quad \Pi_{o}^{N C}=\frac{1}{8(n+1)^{2}} \frac{X^{2}}{b}$

$\Pi_{d}^{N C}=\frac{1}{16(n+1)^{2}} \frac{X^{2}}{b} ; \quad C S^{N C}=\frac{1}{32(n+1)^{2}} \frac{X^{2}}{b}$

and the total welfare

$S W^{N C}=\frac{8 n+7}{32(n+1)^{2}} \frac{X^{2}}{b}$

In the next section we assume that compensation transfers are obtained by negotiation. The programs of the TSO and DSO remain the same.

\subsection{The negotiation protocols}

To gain a thorough understanding of the bargaining process, we consider the three following protocols (see Table 1): Bilateral bargaining (BB), Sequential Bargaining (SQ) and Multilateral Bargaining (MB). In the BB case, the TSO negotiates with each municipality separately and simultaneously, while in the SB case the TSO negotiates separately and sequentially with each municipality. In the MB case there is a single simultaneous negotiation between the TSO and all the municipalities.

In all cases, negotiations are conducted under perfect information and the outcome of the negotiation, obtained by the Nash bargaining solution (Nash, 1950; Binmore et al., 1986), differs according the protocols. The Nash bargaining solution corresponds to a pure bargaining problem meaning that the agreement of all parties involved is necessary to the creation of a positive surplus. All the negotiators involved in the negotiation have thus a veto right and consequently unanimity of all the parties is required to get an agreement. It differs for instance from the paper of Mueller (2016) which assumes that communities can form different sub-coalitions and then reach different partial agreements. It allows him to use a different concept with the Shapley value. In our paper, subcoalitions have no power.

We also assumed that all the negotiators have the same bargaining power. Such an assumption allows us to focus on the impact of each bargaining procedure on the outcome. Of course by assuming that a player has more bargaining power because he is less risk

Table 1

Negotiation types for each protocols.

\begin{tabular}{llll}
\hline Protocols/type & Simultaneous & Separate & Sequential \\
\hline BB & $\checkmark$ & $\checkmark$ & \\
SB & $\checkmark$ & $\checkmark$ & $\checkmark$ \\
MB & $\curlyvee$ & & \\
\hline
\end{tabular}


adverse than his opponent in the Nash Bargaining game or more patient than his opponent in the Rubinstein Bargaining game, he will able to obtain a higher share of the surplus. But the aim of the comparison between several procedures is to show how a player can be better off with a bargaining protocol. It suggests that the difference in outcome between players is the result in the difference of the protocols. Each protocol will then imply different outcomes for the involved parties.

(i) Bilateral bargaining (BB): the TSO negotiates with each municipality separately and simultaneously. Using Eqs. (1) and (2), the Nash bargaining solution (NBS) is solution of

$$
\max _{w_{i}} V_{i}\left(w_{i}\right) \Pi_{o}\left(w_{i}, W_{-i}\right) \text { for } i=1, \ldots, n
$$

(ii) Sequential bargaining (SB): the TSO negotiates with each municipality in a sequential manner knowing that an agreement has been reached in the previous stage. The NBS solves the system:

$$
\left\{\begin{array}{c}
\max _{w_{1}} V_{1}\left(w_{1}\right) \Pi_{o}\left(w_{1}, w_{2}, \ldots, w_{n}\right) \\
\vdots \\
\max _{w_{i}} V_{i}\left(w_{i}\right) \Pi_{o}\left(w_{1}^{*}, \ldots, w_{i-1}^{*}, w_{i}, w_{i+1}, \ldots, w_{n}\right) \\
\vdots \\
\max _{w_{n}} V_{n}\left(w_{n}\right) \Pi_{o}\left(w_{1}^{*}, w_{2}^{*}, \ldots, w_{n-1}^{*}, w_{n}\right)
\end{array}\right.
$$

(iii) Multilateral bargaining (MB): the TSO negotiates with all the municipalities at the same time. The NBS is solution of

$$
\max _{w_{i}} \prod_{i=1}^{n} V_{i}\left(w_{i}\right) \times \Pi_{o}\left(w_{i}, W_{-i}\right)
$$

The three bargaining protocols are over the transfer $w_{i}$ paid by the TSO to the municipalities. Then based on the equilibrium transfers $w_{i}$, the TSO maximizes his payoff by setting his tariff $t_{0}$ and then the DSO his tariff $t_{d}$. All the details of the derivation are in Appendix A.
Table 2

Results for net compensations.

\begin{tabular}{lll}
\hline Cases/net compensation & Total $(W-D)$ & Individual $\left(w_{i}-d_{i}\right)$ \\
\hline NC & $\frac{n}{1+n}$ & $\frac{1}{1+n}$ \\
BB & $\frac{n}{n+3}$ & $\frac{1}{n+3}$ \\
SB & $1-\left(\frac{3}{4}\right)^{n}$ & $\frac{1}{4}\left(\frac{3}{4}\right)^{i-1}$ \\
MB & $\frac{n}{2(n+1)}$ & $\frac{1}{2(n+1)}$ \\
\hline
\end{tabular}

Note: Each term for total and individual net compensations is multiplied by $\frac{X}{b}=$ $\frac{a}{b}-c_{d}-c_{0}-D$. This term represents the part of the grid tariff dedicated to the compensation, once all the costs of the infrastructures have been taken into account. The net compensation is consequently limited by the ceiling tariff for consumers $\left(\frac{a}{b}\right)$.

\section{Results}

In the following section, we explore the results of the negotiation protocols in terms of level of compensations (Proposition 1), payoff of each agent (Proposition 2) and social welfare (Proposition 3), with reference to the benchmark situation (the non-cooperative outcome). See Appendix A for a presentation of the calculations.

Proposition 1. For all municipalities, the non-cooperative case and the sequential bargaining procedure lead to higher net total compensation $(W-D)$. Taking individually, the non-cooperative case maximizes the net compensation $\left(w_{i}-d_{i}\right)$ of a single municipality.

Total net compensations increase with the number of municipalities involved in the project. The total net compensations transferred to the $n$ municipalities $(W-D)$ are higher with the non-cooperative case up to $n=7$. It is then sequential bargaining which leads to higher net compensations (for $n>7$ ). Multilateral bargaining transferred less compensation to municipalities than in the other protocols (for all $n$ ). These results are shown in Fig. 2a and Table 2.

Looking at the individual net compensation paid to a single municipality $\left(w_{i}-d_{i}\right)$, we see that it is a decreasing function of the number of municipalities involved in the project (see Fig. $2 \mathrm{~b}$ ). The non-cooperative case maximizes the individual net compensation for a municipality. Sequential bargaining leads to an unequal distribution of compensation between municipalities and introduces a strategic dimension in terms of negotiation order. It is in the best interest of a municipality to be in the negotiation first positions. From

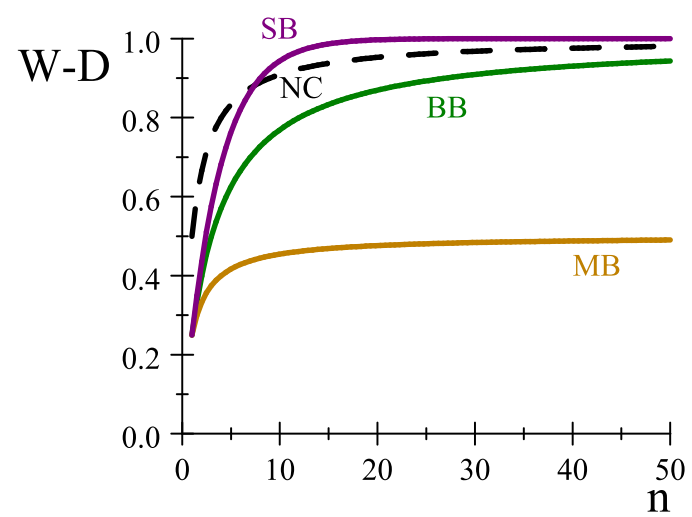

a. Total $(W-D)$

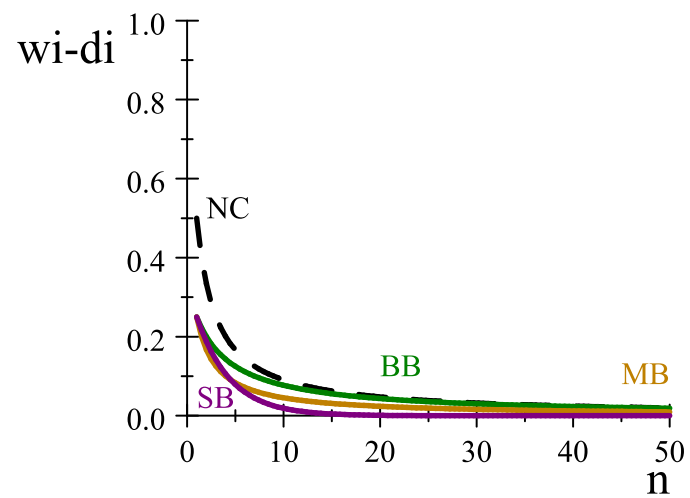

b. Individual $\left(w_{i}-d_{i}\right)$

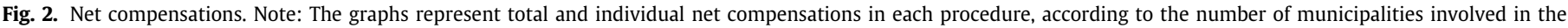

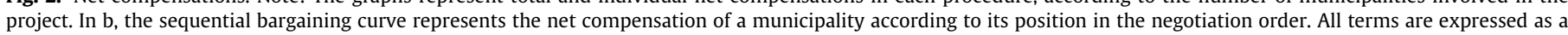
share of $X / b$. 
Table 3

Results for the payoff of each agent.

\begin{tabular}{lllll}
\hline Payoff/cases & $\mathrm{NC}$ & $\mathrm{BB}$ & $\mathrm{SB}$ & $\mathrm{MB}$ \\
\hline$V_{i}$ & $\frac{1}{4(n+1)^{2}}$ & $\frac{3}{4(n+3)^{2}}$ & $\frac{1}{16}\left(\frac{3}{4}\right)^{n}\left(\frac{3}{4}\right)^{i-1}$ & $\frac{n+2}{16(n+1)^{2}}$ \\
$V$ & $\frac{n}{4(n+1)^{2}}$ & $\frac{3 n}{4(n+3)^{2}}$ & $\frac{1}{16}\left(\frac{3}{4}\right)^{n}\left(4-4\left(\frac{3}{4}\right)^{n}\right)$ & $\frac{n(n+2)}{16(n+1)^{2}}$ \\
$\Pi_{0}$ & $\frac{1}{8(n+1)^{2}}$ & $\frac{9}{8(n+3)^{2}}$ & $\frac{1}{8}\left(\frac{3}{4}\right)^{2 n}$ & $\frac{(n+2)^{2}}{32(n+1)^{2}}$ \\
$\Pi_{d}$ & $\frac{1}{16(n+1)^{2}}$ & $\frac{9}{16(n+3)^{2}}$ & $\frac{1}{16}\left(\frac{3}{4}\right)^{2 n}$ & $\frac{(n+2)^{2}}{64(n+1)^{2}}$ \\
$C S$ & $\frac{1}{32(n+1)^{2}}$ & $\frac{9}{32(n+3)^{2}}$ & $\frac{1}{32}\left(\frac{3}{4}\right)^{2 n}$ & $\frac{(n+2)^{2}}{128(n+1)^{2}}$ \\
\hline
\end{tabular}

Note: Each term for $V_{i}, V, \Pi_{0}, \Pi_{d}$ and $C S$ is multiplied by $\frac{X^{2}}{b}$.

the fifth position, a municipality will receive less compensation than with any other procedures.

Sequential bargaining is however the protocol which maximizes the total amount of net compensations paid to all municipalities (from $n>7$ ). At each round of the negotiation, the TSO needs to reach an agreement to get the right to bargain with the next municipality. The position of the TSO is then not profitable in terms of compensations in sequential bargaining. This leads the TSO to pay more monetary transfers. In a bilateral negotiation, the TSO is also in a weak position with respect to the municipalities. It has to bargain with each municipality one by one as if the negotiation is the last one and will allow him to build the line. Multilateral bargaining is here the most profitable procedure for the TSO. This protocol refers to the cooperative solution where both municipalities and the TSO have a veto right.
Proposition 2. Multilateral bargaining maximizes the payoff of each agent when the number of municipalities involved is larger than 5. The municipalities payoff $\left(V=\sum_{i=1}^{n} V_{i}\right)$ is higher than that of the other agents.

Resolution of the bargaining game gives the payoff for each player: the municipalities utilities, the TSO payoff, the DSO payoff, the consumer surplus. Analytical results are displayed for each protocols in Table 3 and in Fig. 3.

We see from Fig. 3 that multilateral bargaining maximizes the payoff of each agent when the number of municipalities involved is larger than 5 . The payoffs remain stable with multilateral bargaining, regardless of the number of municipalities involved, whereas they are decreasing with the other procedures.

The procedure maximizing the total payoff of all municipalities $(V)$ is the non-cooperative case for $n=1$, sequential bargaining for $n=2$, bilateral bargaining for $n \in[3 ; 4]$ and is then multilateral bargaining from $n \geq 5$ (Fig. 3a). Results show that all the bargaining protocols we have considered can be chosen by the involved parties.

Proposition 1 shows that total net compensation increases quickly between 1 and 5 municipalities involved in the project in the NC, SB and BB cases. From $n=5$, total net compensation already reaches a very high level in these procedures, and affects grid tariffs (because compensation is a fraction of the maximum grid tariff, see Table 2). Procedures involving high levels of compensation lead to relatively high grid tariffs $\left(t_{o}\right.$ and $\left.t_{d}\right)$ to cover the additional costs for the TSO. This leads to lower demand, which impacts the utility

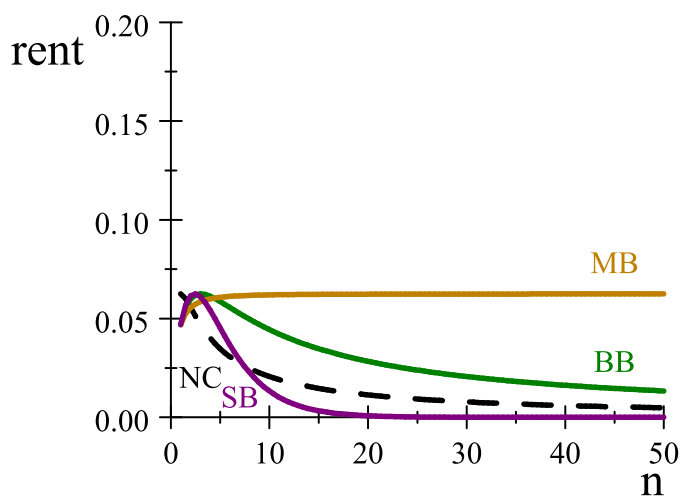

a. Municipalities $(V)$

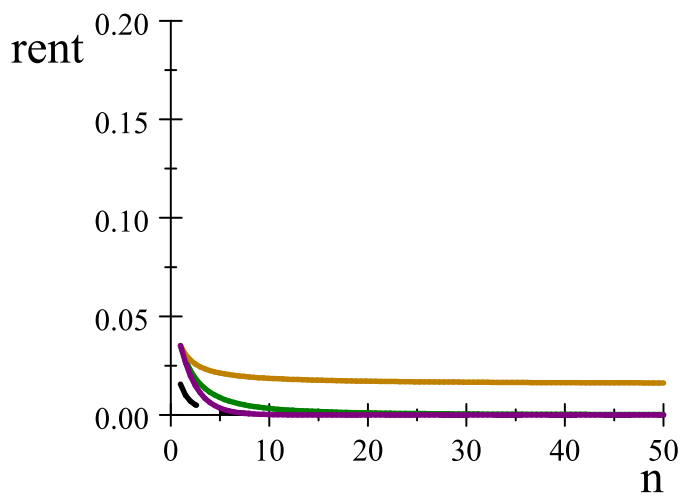

c. $\mathrm{DSO}\left(\Pi_{d}\right)$

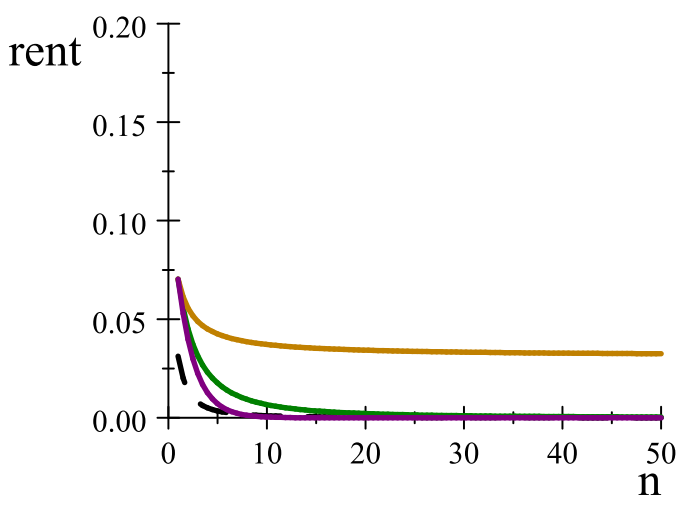

b. $\operatorname{TSO}\left(\Pi_{o}\right)$

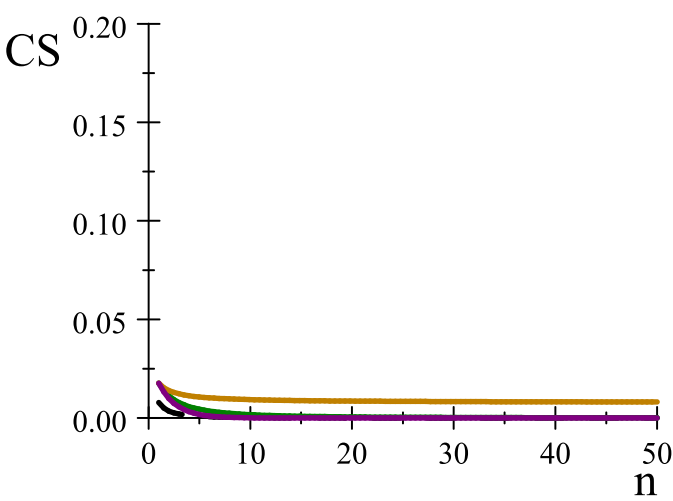

d. Consumers $(C S)$

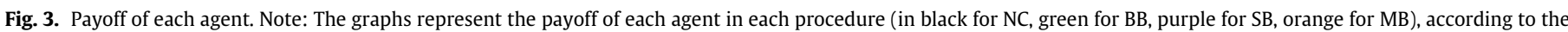
number of municipalities involved in the project. All terms are expressed as a share of $X^{2} / b$. 
function of the municipalities (Eq. (1)). The procedures maximizing net compensation (NC or SB) does not therefore maximize the municipalities payoff.

We observe the same result when reasoning for a single municipality $\left(V_{i}\right)$. As with compensation, the payoff of a municipality with sequential bargaining depends on its position in the negotiation order. There is an advantage for a municipality in being in the very first position in a negotiation because it can get a higher share of the surplus. The following municipalities then compete for a lower share. Such a result is obtained in the bargaining literature (see Clark and Pereau, 2008, 2009). Fig. A.1 in Appendix A shows as an example the possible payoff for a single municipality in the sequential case up to $n=10$.

Proposition 2 also shows that multilateral bargaining is the most profitable procedure for the TSO. It is not surprising to see this protocol maximizing the TSO profit (Fig. 3b). In the vertical relations model, both the DSO and consumers are impacted by the outcome of the negotiations. Based on the previous analysis, multilateral bargaining is logically also the most profitable procedure for these agents (Fig. $3 \mathrm{c}$ and d). Since it minimizes the net compensations paid to municipalities, this procedure conversely maximizes the consumers surplus.

In the end, the municipalities payoff is higher than that of the other agents, for each procedure. We have

$V>\Pi_{o}>\Pi_{d}>C S$

Proposition 3. Multilateral bargaining maximizes the social welfare (SW) whatever the number of municipalities.

The sum of all the payoffs gives the social welfare (Eq. (6)), i.e. the overall surplus of each procedure:

$$
\begin{array}{rlrl}
S W_{N C} & =\left(\frac{8 n+7}{32(n+1)^{2}}\right) \frac{X^{2}}{b} ; & S W_{B B} & =\left(\frac{24 n+63}{32(n+3)^{2}}\right) \frac{X^{2}}{b} \\
S W_{S B} & =\frac{1}{32}\left(\frac{3}{4}\right)^{n}\left(8-\left(\frac{3}{4}\right)^{n}\right) \frac{X^{2}}{b} ; & S W_{M B}=\left(\frac{15 n^{2}+44 n+28}{128(n+1)^{2}}\right) \frac{X^{2}}{b}
\end{array}
$$

Fig. 4 shows that the social welfare is maximized for the multilateral bargaining (see Proposition 3). From $n>7$, sequential bargaining leads to a lower social welfare than in all other procedures and then tends to zero. For all agents, we have

$$
S W_{M B}>S W_{B B}>S W_{N C}>S W_{S B}
$$

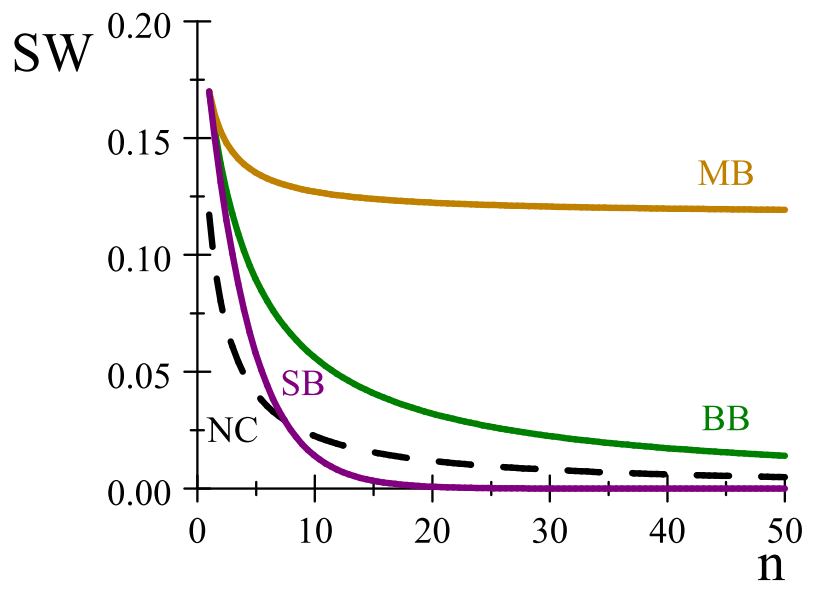

Fig. 4. Social welfare. Note: The graph represents the social welfare in each procedure, according to the number of municipalities involved in the project. All terms are expressed as a share of $X^{2} / b$.
A large proportion of the social welfare is allocated to the municipalities (Fig. 5), especially with the procedures leading to high level of compensation (NC or SB). Distribution among agents is more balanced in the multilateral case.

Finally we can summarize the results as follows:

(i) when $n<5$, the number of municipalities is small and the different bargaining procedures can be chosen. A single municipality will prefer not to negotiate and plays noncooperatively. Two municipalities will prefer the sequential case while bilateral bargaining will be preferred by 3 and 4 municipalities.

(ii) when $n \geq 5$, the number of municipalities increases and multilateral bargaining is preferable for all the agents, including the municipalities. The high level of compensations following the non-cooperative case or the sequential bargaining lead to relatively higher grid tariffs, thus reducing the demand and the quantity sold (Table 4). The TSO should seek to put in place multilateral bargaining to achieve a fairer outcome for all the agents.

\section{Conclusion}

Unanimous acceptance by host municipalities is not the only yardstick of success in negotiations over the siting of new electric power transmission lines. One of the most critical decisions to be made by a TSO is how best to negotiate compensation, bearing in mind the interests of other beneficiaries of a grid expansion project (including the electricity consumers) and the strategies they pursue. This paper documents on the role of bargaining protocols in achieving efficient and socially-optimal compensation payments to host municipalities. The negotiation procedure between the TSO and heterogeneous host municipalities for the payment of compensations is described as a bargaining game. The interaction between the TSO and DSO when supplying electricity to end users is based on a vertical $X^{2}$ relations model (a representative model for France and other countries where TSO and DSO are still monopolies which are governed by the energy authorities).

The Nash bargaining solution is obtained from three protocol situations, and compared with the non-cooperative case in which each player maximizes his own payoff with respect to his decision variable. The first protocol refers to bilateral bargaining where each municipality negotiates separately and simultaneously with the TSO; the second is a sequential negotiation where TSO negotiates with each municipality by backward-induction; and lastly a multilateral bargaining where all municipalities simultaneously negotiate together with the TSO.

Our results shed light on how the TSO and host municipalities reach an agreement through bargaining process and determine fair, efficient and optimal levels of compensation for the installation of a new transmission line. We show that all the bargaining protocols we have analysed can be chosen by the host municipalities. The negotiation rule would affect the outcome of each agent and has a significant influence on the compensation amount to be paid to host municipalities. However, the negotiation procedure that enables municipalities to obtain the highest amount of compensation (non-cooperative or sequential bargaining) do not necessarily lead to the optimal outcome for them. Because a host municipality's revenue is a function of electricity demand, higher compensation will lead to a reduced payoff of other agents further down the vertical hierarchy. An increase in grid tariffs to cover the costs of high compensation will impact demand, which itself is linked to the payoffs of all other agents (municipalities, TSO, DSO). In addition, the sequential bargaining procedure is associated with inequality between municipalities, and 

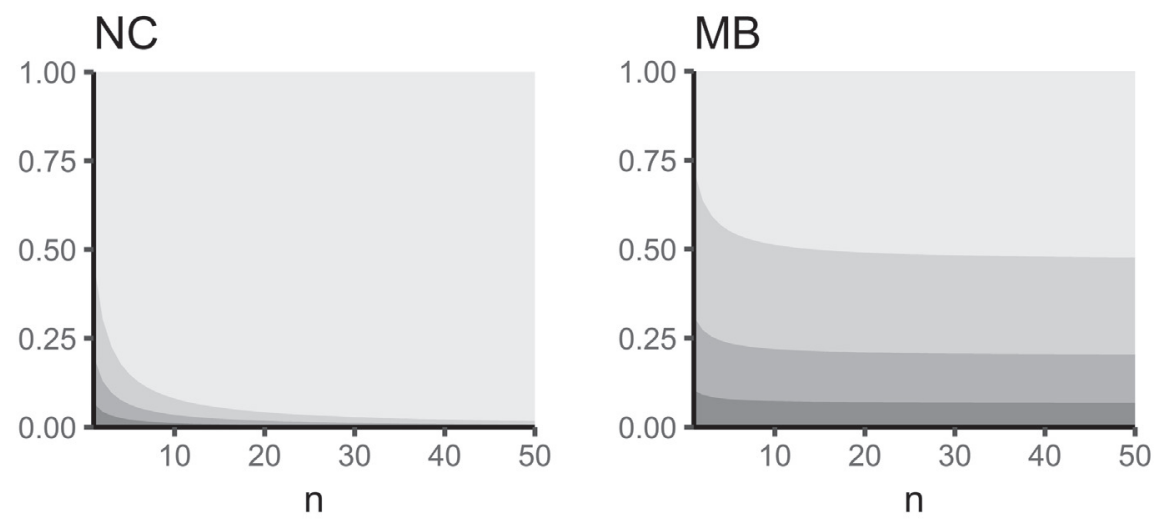

$\mathrm{BB}$
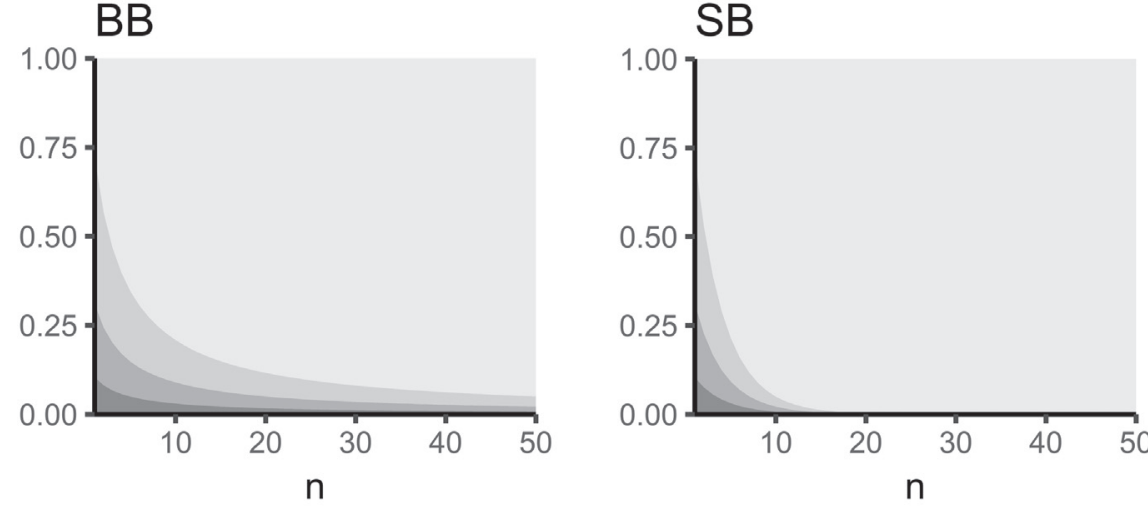

Municipalities
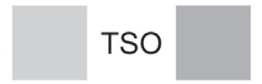

DSO

Consumers

Fig. 5. Social welfare distribution between agents. Note: The graphs represent the share of social welfare for each agent in each procedure, according to the number of municipalities involved in the project.

the lowest revenue for all agents, hence a minimal social welfare value.

They also suggest that when the number of municipalities is high, multilateral bargaining yields the cooperative outcome which is also the most favorable procedure for all the stakeholders. When the number of municipalities is low, several cases can occur. A single municipality will act non-cooperatively. Two municipalities will prefer the sequential case while bilateral bargaining will be preferred by three and four municipalities. It shows that the current strategy of the French TSO to favor bilateral negotiations is not efficient when the number of municipalities is large.

Such a finding puts forward that the choice of the bargaining procedure may account for the success of community benefit negotiation and the need for an adequate regulatory framework. However, determining which bargaining procedure give the most profitable agreement for all agents (municipalities, TSO, DSO and

Table 4

Results for grid tariffs and demand.

\begin{tabular}{llll}
\hline Cases & $t_{0}$ & $t_{d}$ & $Q\left(t_{d}\right)$ \\
\hline $\mathrm{NC}$ & $\frac{a}{b}-c_{d}-\left(\frac{1}{2(1+n)}\right) \frac{X}{b}$ & $\frac{a}{b}-\left(\frac{1}{4(1+n)}\right) \frac{X}{b}$ & $\frac{1}{4(1+n)} X$ \\
$\mathrm{BB}$ & $\frac{a}{b}-c_{d}-\left(\frac{3}{2(n+3)}\right) \frac{X}{b}$ & $\frac{a}{b}-\left(\frac{3}{4(n+3)}\right) \frac{X}{b}$ & $\frac{3}{4(n+3)} X$ \\
$\mathrm{SB}$ & $\frac{a}{b}-c_{d}-\left(\frac{1}{2}\left(\frac{3}{4}\right)^{n}\right) \frac{X}{b}$ & $\frac{a}{b}-\left(\frac{1}{4}\left(\frac{3}{4}\right)^{n}\right) \frac{X}{b}$ & $\frac{1}{4}\left(\frac{3}{4}\right)^{n} X$ \\
$\mathrm{MB}$ & $\frac{a}{b}-c_{d}-\left(\frac{n+2}{4(1+n)}\right) \frac{X}{b}$ & $\frac{a}{b}-\left(\frac{n+2}{8(1+n)}\right) \frac{X}{b}$ & $\frac{n+2}{8(n+1)} X$ \\
\hline
\end{tabular}

consumers) is only the first step of the analysis since real-life negotiations are also characterized by asymmetric information issues or more complex strategic considerations. In future work, it will be extremely important to recognize more explicitly the heterogeneity of municipalities' strategies. It may be of interest for some host municipalities to form coalition when negotiating with the TSO, while other may prefer to negotiate as singletons. The conditions under which both groups can co-exist would be a first extension of our model. A second extension will be to introduce additional interactions in the vertical model. Moreover, it has to be emphasized that municipalities' decisions and consumers' utility function have an influence each other through an indirect link, via a variation of the grid tariff which is reflected directly and explicitly in the electricity tariff for consumers. Finally, although distributing individual financial compensation to residents of host municipalities is a highly debated policy issue, one can argue that how financial compensation of host communities is designed (a reduced electricity tariff for local inhabitants instead of direct investment in collective public goods) may also affect negotiation outcomes.

To conclude, it is difficult and complex to disentangle the different channels through which the financial compensation offer to host communities could be negotiated to generate a win win solution for all parties (TSO, host municipalities, DSO and final consumers). However, analyzing solutions other the status quo within a bargaining theoretical framework could be an important approach for explication of host communities' agreement on power line projects needed for achieving energy transition. 


\section{Acknowledgements}

The research leading to these results has received the financial support of Rte (the French transmission system operator) through a doctoral grant to Olivier Joalland.

\section{Appendix A}

\section{A.1. List of variables and notation}

\begin{tabular}{llll}
\hline Variable & Interpretation & Variable & Interpretation \\
\hline$i=1, \ldots, n$ & Municipality & $t_{d}$ & Tariff set by the DSO \\
$d_{i}$ & Damage of $i$ & $c_{d}$ & Fixed cost of the DSO \\
$w_{i}$ & Compensation of $i$ & $Q$ & Demand function \\
$V_{i}$ & Payoff of $i$ & $a$ & Intercept of the demand function \\
$D=\sum_{i=1}^{n} d_{i}$ & Total damage & $b$ & Slope of the demand function \\
$W=\sum_{i=1}^{n} w_{i}$ & Total compensation & $X$ & Surplus created \\
$V=\sum_{i=1}^{n} V_{i}$ & Total payoff & $C S$ & Consumer surplus \\
$\Pi_{0}$ & Payoff of the TSO & $S W$ & Social welfare \\
$t_{0}$ & Tariff set by the TSO & $B B$ & Bilateral protocol \\
$c_{0}$ & Fixed cost of the TSO $S B$ & Sequential protocol \\
$\Pi_{d}$ & Payoff of the DSO & $M B$ & Multilateral protocol \\
\hline
\end{tabular}

With $X=a-b\left(c_{d}+c_{o}+D\right)>0$ the created surplus along the value chain.

\section{A.2. Non-cooperative case}

The maximization program of the DSO is

$$
\max _{t_{d}} \Pi_{d}=\left(t_{d}-t_{o}-c_{d}\right)\left(a-b t_{d}\right)
$$

FOC gives

$t_{d}=\frac{1}{2}\left(\frac{a}{b}+c_{d}+t_{o}\right)$

Substitute Eq. (A1) in Eq. (4) yields

$Q=\frac{1}{2}\left(a-b\left(c_{d}+t_{0}\right)\right)$

Substitute Eq. (A2) in the maximization program of the TSO (Eq. (2)) gives

$\max _{t_{o}} \Pi_{o}=\frac{1}{2}\left(t_{o}-W-c_{o}\right)\left(a-b\left(c_{d}+t_{o}\right)\right)$

FOC yields the tariff

$t_{o}=\frac{1}{2}\left(\frac{a}{b}+W+c_{o}-c_{d}\right)$

Substitute Eq. (A3) in Eq. (A2) gives

$Q=\frac{1}{4}\left(a-b\left(W+c_{d}+c_{0}\right)\right)$

The maximization program for a municipality $i$ can be written as $\max _{w_{i}} V_{i}=\frac{1}{4}\left(w_{i}-d_{i}\right)\left(a-b\left(W+c_{d}+c_{o}\right)\right)$

FOC gives

$w_{i}=\frac{a}{b}-c_{d}-c_{o}-W+d_{i}$
Taking the sum yields

$W^{N C}=\frac{n}{1+n} \frac{X}{b}+D$

Simple calculations give the other expressions detailed in Section 3.1 and in Tables 2-4.

\section{A.3. Bilateral bargaining}

Using Eqs. (2) and (1), the NBS for the bilateral bargaining is solution of

$$
\max _{w_{i}} \frac{1}{32 b}\left(w_{i}-d_{i}\right)\left(a-b\left(W+c_{d}+c_{o}\right)\right)^{3}
$$

FOC gives

$w_{i}=\frac{1}{3}\left(\frac{a}{b}-W-c_{d}-c_{o}\right)+d_{i}$

Taking the sum gives

$W=\frac{1}{n+3}\left(n\left(\frac{a}{b}-c_{d}-c_{o}\right)+3 D\right)$

Substitute in Eq. (A5) gives the individual and total compensations

$w_{i}^{B B}=d_{i}+\frac{1}{n+3} \frac{X}{b}$

$W^{B B}=D+\frac{n}{n+3} \frac{X}{b}$

Simple calculations give the other expressions detailed in Tables 2-4.

\section{A.4. Multilateral bargaining}

Using Eqs. (2) and (1), the NBS for the multilateral bargaining is solution of

$\max _{w_{i}} \frac{1}{2^{2 n+3} b} \prod_{i=1}^{n}\left(w_{i}-d_{i}\right)\left(a-b\left(W+c_{d}+c_{o}\right)\right)^{n+2}$

FOC gives

$w_{i}=\frac{1}{n+2}\left(\frac{a}{b}-W-c_{d}-c_{o}\right)+d_{i}$

Taking the sum

$W=\frac{1}{2(n+1)}\left(n\left(\frac{a}{b}-c_{d}-c_{o}\right)+(n+2) D\right)$

Substitute in Eq. (A6) gives the individual and total compensations:

$w_{i}^{M B}=d_{i}+\frac{1}{2(n+1)} \frac{X}{b}$

$W^{M B}=D+\frac{n}{2(n+1)} \frac{X}{b}$

Simple calculations give the other expressions detailed in Tables 2-4. 


\section{A.5. Sequential bargaining}

We solve the model by backward induction, starting with municipality $n$, then $n-1, n-2$, until the first 1 . Concerning the last round of negotiation between the TSO and $n$, we have

$\max _{w_{n}} \frac{1}{32 b}\left(w_{n}-d_{n}\right)\left(a-b\left(\sum_{i=1}^{n} w_{i}+c_{d}+c_{o}\right)\right)^{3}$

\section{FOC gives}

$w_{n}=\frac{1}{4}\left(\frac{a}{b}-c_{d}-c_{o}+3 d_{n}-\sum_{i=1}^{n-1} w_{i}\right)$

then between the TSO and $n-1$ we have

$\max _{w_{n-1}} \frac{1}{32 b}\left(w_{n-1}-d_{n-1}\right)\left(a-b\left(w_{n}+\sum_{i=1}^{n-1} w_{i}+c_{d}+c_{o}\right)\right)^{3}$

Substitute Eq. (A7) by its expression gives

$\max _{w_{n-1}} \frac{1}{32 b}\left(\frac{3}{4}\right)^{3}\left(w_{n-1}-d_{n-1}\right)\left(a-b\left(\sum_{i=1}^{n-1} w_{i}+d_{n}+c_{d}+c_{o}\right)\right)^{3}$

FOC gives

$w_{n-1}=\frac{1}{4}\left(\frac{a}{b}-c_{d}-c_{o}+3 d_{n-1}-\sum_{i=1}^{n-2} w_{i}-d_{n}\right)$

The same process applies until the first negotiation round between the TSO and 1 .

A generic negotiation between the TSO and a municipality $i$ can be written as

$\max _{w_{i}} \frac{1}{32 b}\left(\left(\frac{3}{4}\right)^{n-i}\right)^{3}\left(w_{i}-d_{i}\right)\left(a-b\left(\sum_{j=i+1}^{n} d_{j}+\sum_{j=1}^{i} w_{j}+c_{d}+c_{0}\right)\right)^{3}$

From Eqs. (A7) and (A8), we deduce

$w_{i}=\frac{1}{4}\left(\frac{a}{b}-c_{d}-c_{o}+3 d_{i}-\sum_{j=1}^{i-1} w_{j}-\sum_{j=i+1}^{n} d_{j}\right)$

It gives

$w_{i}^{S B}=d_{i}+\frac{1}{4}\left(\frac{3}{4}\right)^{i-1} \frac{X}{b}$

$\sum_{i=1}^{n-1}\left(\frac{3}{4}\right)^{i-1}$ is a geometric sequence and can be rewritten as $4-$ $4\left(\frac{3}{4}\right)^{n}$. So we have

$W^{S B}=D+\left(1-\left(\frac{3}{4}\right)^{n}\right) \frac{X}{b}$

Simple calculations give the other expressions detailed in Tables 2-4.

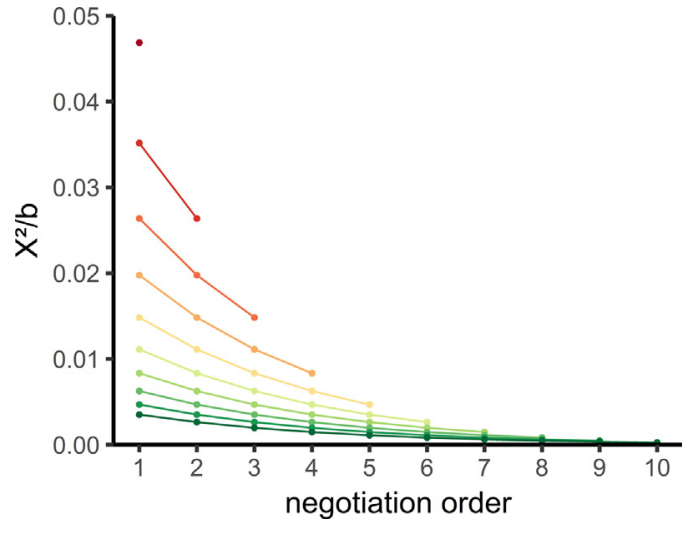

Fig. A.1. Payoff of a single municipality with sequential bargaining. Note: A point represents the payoff of a municipality according to its position in the negotiation order and to the number of municipalities involved in the project.

\section{References}

Atkinson, G., Day, B., Mourato, S., 2006. Underground or overground? Measuring the visual disamenity from overhead electricity transmission lines. Environmental Valuation in Developed Countries: Case Studies. pp. 213-239.

Banez-Chicharro, F., Olmos, L., Ramos, A., Latorre, J.M., 2017. Estimating the benefits of transmission expansion projects: an Aumann-Shapley approach. Energy 118, 1044-1054.

Binmore, K., Rubinstein, A., Wolinsky, A., 1986. The Nash bargaining solution in economic modelling. RAND J. Econ. 17 (2), 176-188.

Cain, N.L., Nelson, H.T., 2013. What drives opposition to high-voltage transmission lines? Land Use Policy 33, 204-213.

Ciupuliga, A.R., Cuppen, E., 2013. The role of dialogue in fostering acceptance of transmission lines: the case of a France-Spain interconnection project. Energy Policy 60, 224-233.

Clark, D., Pereau, J.C., 2008. Passing the buck in sequential bargaining. B.E. J. Theor Econ. 8 (1).Article 26.

Clark, D., Pereau, J.C., 2009. Fragmented property rights and royalty bargaining. J. Econ. Behav. Organ. 72, 546-553.

Coase, R.H., 1960. The problem of social cost. J. Law Econ. 3, 1.

Cohen, J., Moeltner, K., Reichl, J., Schmidthaler, M., 2016. An empirical analysis of local opposition to new transmission lines across the EU-27. Energy J. 37 (3).

Commission, E., 2010. Commission regulation (EU) No. 838/2010 of 23 September 2010 on laying down guidelines relating to the inter-transmission system operator compensation mechanism and a common regulatory approach to transmission charging.

Devine-Wright, P., 2012. Explaining NIMBY objections to a power line: the role of personal, place attachment and project-related factors. Environ. Behav.

ENTSO-e, 2014. Ten-year network development plan 2014. Technical Report.

Fetz, A., Filippini, M., 2010. Economies of vertical integration in the Swiss electricity sector. Energy Econ. 32 (6), 1325-1330.

Gately, D., 1974. Sharing the gains from regional cooperation: a game theoretic application to planning investment in electric power. Int. Econ. Rev. 15 (1), 195-208.

Glachant, J.M., Ruester, S., 2014. The EU internal electricity market: done forever? Util. Policy 31, 221-228.

Hart, O., Tirole, J., Carlton, D.W., Williamson, O.E., 1990. Vertical integration and market foreclosure. Brookings papers on economic activity. Microeconomics 205-286

Hasan, K.N., Saha, T.K., Chattopadhyay, D., Eghbal, M., 2014. Benefit-based expansion cost allocation for large scale remote renewable power integration into the Australian grid. Appl. Energy 113, 836-847.

Horn, H., Wolinsky, A., 1988. Bilateral monopolies and incentives for merger. RAND J. Econ. 19 (3), 408-419.

Hyland, M., Bertsch, V., 2018. The role of community involvement mechanisms in reducing resistance to energy infrastructure development. Ecol. Econ. 146, 447-474. April.

Joskow, P.L., 2014. Incentive regulation in theory and practice: electricity distribution and transmission networks Economic Regulation and Its Reform: What Have We Learned?. pp. 291-344.

Keir, L., Watts, R., Inwood, S., 2014. Environmental justice and citizen perceptions of a proposed electric transmission line. Community Dev. 45 (2), 107-120.

Komendantova, N., Battaglini, A., 2016. Beyond decide-announce-defend (DAD) and not-in-my-backyard (NIMBY) models? Addressing the social and public acceptance of electric transmission lines in Germany. Energy Res. Soc. Sci. 22, 224-231.

Krishna, V., Serrano, R., 1996. Multilateral bargaining. Rev. Econ. Stud. 63 (1), 61-80.

Kunreuther, H., Easterling, D., 1996. The role of compensation in siting hazardous facilities. J. Policy Anal. Manage. 15 (4), 601-622. 
Lienert, P., Sutterlin, B., Siegrist, M., 2018. Public acceptance of high-voltage power lines: the inuence of information provision on undergrounding. Energy Policy 112 (Supplement C), 305-315.

Menges, R., Beyer, G., 2014. Underground cables versus overhead lines: do cables increase social acceptance of grid development? Results of a contingent valuation survey in Germany. Int. J. Sustain. Energy Plann. Manag. 3 (0), 33-48.

Mueller, D., 2016. Grid extension in German backyards: a game-theory rationale. J. Environ. Plan. Manag. 60 (3), 437-461.

Muthoo, A., 1999. Bargaining Theory With Applications. Cambridge University Press.

Nash, J.F., 1950. The bargaining problem. Econometrica 18, 155-162.

Navrud, S., Ready, R.C., Magnussen, K., Bergland, O., 2008. Valuing the social benefits of avoiding landscape degradation from overhead power transmission lines: do underground cables pass the benefit-cost test? Landsc. Res. 33 (3), 281-296.

Peréz-Arriaga, I.J., 2014. Regulation of the Power Sector. Springer Science \& Business Media.

Rey, P., Verge, T., 2004. Bilateral control with vertical contracts. RAND J. Econ. 35 (4), $728-746$.

RGI, 2016. Community payments, case studies from across Europe. Technical Report. RGI.,

Roustaei, M., Sheikh-El-Eslami, M.K., Seifi, H., 2014. Transmission cost allocation based on the users benefits. Int. J. Electr. Power Energy Syst. 61, 547-552.
Rte, 2016. Schema decennal de developpement du reseau. Technical Report.

Rubinstein, A., 1982. Perfect equilibrium in a bargaining model. Econometrica 50 (1), 97-109.

Spath, L., Scolobig, A., 2017. Stakeholder empowerment through participatory planning practices: the case of electricity transmission lines in France and Norway. Energy Res. Soc. Sci. 23, 189-198.

Späth, L., Scolobig, A., Patt, A., Hildebrand, J., Molinengo, V., Evensen, J., Rudberg, B. Jullier, J., Reyhanloo, T., INSPIRE-Grid, 2014. Improved and enhanced stakeholder participation in reinforcement of electricity grid: establishing the best practices and determining a toolbox. ETH Zurich Research Collection, pp. 74

Spengler, J.J., 1950. Vertical integration and antitrust policy. J. Polit. Econ. 58 (4), 347-352.

Tirole, J., 1988. The Theory of Industrial Organization. MIT Press.

Tobiasson, W., Beestermoller, C., Jamasb, T., 2016. Public engagement in electricity network development: the case of the Beauly-Denny project in Scotland. Econ. Polit. Ind. $1-22$.

Tobiasson, W., Jamasb, T., 2016. The solution that might have been: resolving social conflict in deliberations about future electricity grid development.. Energy Res. Soc. Sci. 17, 94-101. 